\title{
Measuring Systemic Risk: A Risk Management Approach*
}

\author{
Alfred Lehar ${ }^{\dagger}$ \\ Department of Business Studies \\ University of Vienna
}

September 2004

\footnotetext{
${ }^{*}$ A former version of this paper was entitled "Implementing a portfolio perspective in banking supervision". Thanks to Thomas Dangl, Helmut Elsinger, Michael Halling, Patricia Jackson, Cornelia Kullmann, Otto Randl, Suresh Sundaresan, Martin Summer, Konstantinos Tsatsaronis, Josef Zechner, and the participants of the Northern Finance Association Meetings 2001, the German Finance Association Meetings 2001, and the European Finance Association Meetings 2003 for valuable discussions.

${ }^{\dagger}$ University of Vienna, Brünner Strasse 72, A-1210 Wien, Austria. alfred.lehar@univie.ac.at, Tel.: +4314277 38077, Fax.: +431427738074.
} 


\title{
Measuring Systemic Risk: A Risk Management Approach
}

\begin{abstract}
This paper proposes a new method to measure and monitor the risk in a banking system. Standard tools that regulators require banks to use for their internal risk management are applied at the level of the banking system to measure the risk of a regulator's portfolio. Using a sample of international banks from 1988 until 2002, I estimate the dynamics and correlations between bank asset portfolios. To obtain measures for the risk of a regulator's portfolio, I model the individual liabilities that the regulator has to each bank as contingent claims on the bank's assets. The portfolio aspect of the regulator's liability is explicitly considered and the methodology allows a comparison of sub-samples from different countries. Correlations, bank asset volatility, and bank capitalization increase for North American and somewhat for European banks, while Japanese banks face deteriorating capital levels. In the sample period, the North American banking system gains stability while the Japanese banking sector becomes more fragile. The expected future liability of the regulator varies substantially over time and is especially high during the Asian crisis starting in 1997. Further analysis shows that the Japanese banks contribute most to the volatility of the regulator's liability at that time. Larger and more profitable banks have lower systemic risk and additional equity capital reduces systemic risk only for banks that are constrained by regulatory capital requirements.
\end{abstract}

JEL-Codes: C15, E53, G21 


\section{Introduction}

"Second only to its macrostability responsibilities is the central bank's responsibility to use its authority and expertise to forestall financial crises (including systemic disturbances in the banking system) and to manage such crises once they occur." Alan ?

As the integration of financial markets progresses rapidly, regulators and supranational agencies become increasingly worried about systemic risk in the banking sector. The main concern is that the simultaneous failure of several banks would result in a severe economic crisis. The impact of such a banking crisis on the economy can be substantial, as past experiences have shown. ?, for example, find that output falls by an average of $15 \%$ to $20 \%$ of GDP during banking crisis periods. Despite these concerns about system wide problems capital requirements, auditing policies, and deposit insurance premiums do not consider bank interdependencies. Current bank regulation is specified at the individual bank level. The idea behind the current regulatory framework is that there is little risk for the banking system as a whole as long as the default risk of individual banks is low. Even regulators themselves doubt this and try to push bank supervision more towards a system-wide or macroprudential framework 1 During the last years, bank supervisors also forced banks to implement more advanced risk management systems. When a bank assesses the risk of its investment portfolio, it should not only look at the risk of individual exposures but also account for correlations of the exposures. Banks are also forced to be adequately capitalized to survive a major economic shock. Regulators, in contrast, have not implemented this portfolio perspective at the level of the banking system. They do not see the banks under their jurisdiction as portfolio, consider correlations between them, and the ideas and tools of modern risk management have not found their way into prudential bank supervision. This paper closes this gap and attempts to measure risk at the level of the banking system rather than at the level

\footnotetext{
${ }^{1}$ See e.g. ?
} 
of individual banks using standard tools of modern risk management similar to those applied by major banks.

Following ?, I interpret equity as a call option on a bank's assets. Using a time series of observed equity prices and balance sheet information, I back out the market value of a bank's asset portfolio and its associated dynamics. Three key input parameters of this asset process are essential to estimate the risk of a banking system. To explore the threat of a banking crisis, correlation between the values of banks' asset portfolios is the most important factor. In a banking sector with highly correlated asset portfolios, the probability of multiple defaults is high, making positive correlation undesirable for regulators. However, bank fragility is also influenced by financial soundness, because well capitalized banks are able to absorb larger shocks, reducing the probability of failures. Finally bank regulators should be concerned about the volatility of the banks assets, as more volatile banks face a higher probability of default.

An important feature of the portfolio approach is that one can estimate the probability of a systemic crisis, i.e., that a certain fraction of financial institutions (both in terms of numbers as well as in terms of size) will default over a given time horizon. Within the Merton framework, this and other liabilities of the regulator can be modeled as contingent claims on the banks' asset portfolio. The main innovation of this portfolio approach is to include asset correlations in the risk assessment for banking systems. The paper can thus also be seen as proposing a framework for controlling for the part of systemic risk, which arises from correlated asset portfolios 2 Another measure to judge the stability of the banking system is to look at the present value of the expected future shortfall. In the Merton framework, this is equal to the price of a put option. To make the measure more intuitive we can also think of it as the fair upfront deposit insurance premium. Within the framework of the paper one can interpret the liabilities of the

\footnotetext{
${ }^{2}$ The paper does not attempt to capture systemic risk that arises because of contagion, i.e. the failure of individual bank will directly cause failures of other banks because of linkages in the inter-bank market. For the remainder of the paper, the term 'systemic risk' will be used to capture the risk that is due to correlated asset portfolios. ? shows in a theoretical model that banks may have an incentive for aggregate risk shifting to the regulator by investing in correlated portfolios.
} 
regulator as a portfolio of short put options on correlated assets. Using standard risk management techniques, I can estimate the current value as well as the volatility of the regulator's liability. These numbers can be used to estimate the funds that the lender of last resort has to be ready to inject into the banking system or to derive a value-at-risk for the deposit insurance agency, which defines the optimal size of the deposit insurance fund. Using standard value-at-risk tools, the contribution of an individual bank or of a group of banks to the volatility of a deposit insurer's liability can be derived. This allows national regulators to identify the banks with the highest contribution to systemic risk while supra-national agencies like the IMF can identify countries which threaten the stability of the global financial system. In this paper the method is applied to a sample of 149 international banks over a twelve year horizon.

Financial stability varies substantially over time and between countries. Correlations and volatilities of North American banks' asset portfolios have increased dramatically since 1997. Nevertheless, the systemic risk in the North American banking system has decreased over time as banks increased their capitalization. Capitalization of Japanese banks in terms of market values has decreased dramatically over time, causing the Japanese banking system to become very instable. Larger banks have a higher median correlation to other banks and are better capitalized. Banks that are more profitable invest in less risky assets and have a higher equity ratio.

The contribution of North American banks to the risk of the global financial system decreases over time while the major share of systemic risk over the whole sample period stems from the Japanese banks. More profitable and larger banks are less risky in terms of systemic risk. Additional equity capital, the prime instrument of current bank regulation, reduces systemic risk only for those banks that are close to the regulatory minimum capitalization while it has no effect on regulatory unconstrained banks.

This paper only uses information of financial markets and therefore complements other recent research, which quantifies systemic risk only based on detailed, proprietary information submitted to national regulators. ? estimate bilateral inter-bank exposures 
in the Austrian banking system. They have data on the individual banks' exposures to market and credit risk factors and analyze the impact of economic shocks on the banking system. The likelihood of contagious defaults is estimated using a network model of the inter-bank market. They find that correlation of bank asset portfolios contributes more to systemic risk than contagion. ? estimates bilateral exposures from the federal funds market and finds little evidence of contagion following simulated idiosyncratic defaults. While these papers give valuable insights into the risk structure of a particular banking system for national regulators with access to detailed filings, the framework of this paper is well suited for supra-national regulators, international comparisons, and to provide supplementary information for national regulators that is not contained in the banks' periodic reports. Two recent contributions by ? for the U.S. and ? for European banks show that market information can provide additional information to bank regulators that is not contained in standard supervisory reports.

Two other recent studies are related to this paper in their approach to measure systemic risk 3 ? use a structural model to estimate fair deposit insurance premiums for a sample of eight British banks. They calculate long term survival probabilities, estimate the probabilities of multiple failures at one point in time for a ten year horizon, and analyze the impact of equity capital on these default probabilities. This paper extends their research in two ways: On the one hand, a larger, international sample is examined and the evolution of systemic risk over time is computed; on the other hand, this paper derives contributions of individual banks to the systemic risk in the banking system that can be related to individual bank characteristics. ? find a significant increase in stock price correlation of large US banks. The focus of their paper is different from this one as the authors relate correlations to financial consolidation (i.e. increases in market share) 4

\footnotetext{
${ }^{3}$ See also ?, ?, ?, or ? for recent surveys on systemic risk. For theoretical models see ? or ?.

${ }^{4}$ Other studies test for systemic risk by looking at autocorrelations in bank failures (e.g. ?) or at deposit flows (e.g. ? or ?). ? construct a model based on bank survival duration during the great depression. They find that most of the previously identified banking crisis can be explained by bank specific indicators as well as regional and national fundamentals and thus little evidence of contagion.
} 
The approach presented here allows an ongoing assessment of a regulator's total risk over time. Supervisors can identify periods of increased systemic risk before bank failures occur and can set appropriate actions to protect the banking sector. The methodology is easy to implement and the necessary data are publicly available. It also allows national regulators to benchmark the risk in their banking system to the systemic risk in other countries. To my knowledge, this paper is the first to conduct an international comparison of systemic risk. This paper also introduces a new set of indicators of bank system fragility 5 The approach allows computation of an individual bank's contribution to the overall risk of the banking system, which can be used to identify system relevant banks and to compute bank-specific deposit insurance premiums that consider systemic risk.

The rest of the paper is organized as follows: Section 2 explains the methodology, Section 3 describes the sample, Section 4 presents summary statistics on the dynamics of bank asset values. These are used to derive alternative measures of systemic risk in Section 5, and Section 6 concludes.

\section{Methodology}

A bank's asset portfolio, consisting of loans, traded securities and many other items, is refinanced by debt and equity. It is current practice today to judge soundness of a financial institution by looking at accounting data, which are directly observable, and most of the current bank supervision procedures like capital requirements and reports to regulatory agencies are based on accounting values. The actual market value of the assets, that reveals more information on the bank's financial health, is not directly observable 6 This section describes the structural model, which is used to estimate market values of the bank's assets, which will then allow us to estimate the systemic

\footnotetext{
${ }^{5}$ The goal of the paper is to introduce a new methodology to measure risk at the system level and not to propose an action plan for regulators what to do for a given level of systemic risk. Optimal regulatory responses depend on the utility function of the bank supervisor which is not publicly observable.

${ }^{6}$ The dynamics the market value of a bank's liabilities are not important, as the bank is assumed to default whenever the market value of the assets is below the promised payments, which is the book value of liabilities.
} 
risk of a financial system.

In line with a broad stream of literature I choose the market value of the bank's asset portfolio $V$ as the state variable. Following ? and ? corporate securities like debt and equity can then be seen as contingent claims on the assets and priced accordingly 7 This approach is widely used by academics and practitioners to price deposit insurance $(?, ?) 8$, or to assess credit risk (?, ?, and KMV corporation's credit risk model). In the banking literature the Merton framework is also used to evaluate the risk of individual banks over time (?), to assess the government subsidy to individual banks (?), and to test for risk shifting behavior of banks (? and ?).

Assume that the asset value $V$ of the bank follows a geometric Brownian motion with drift $\mu$ and volatility $\sigma$

$$
d V=\mu V d t+\sigma V d z
$$

Then equity $E_{t}$ can be seen as a call option on the bank's assets with a strike price equal to the future notional value of the bank's debt $B$, which is assumed to have a maturity of $T$. I assume that all bank debt is insured and will therefore grow at the risk-free rate 9 The value of bank equity is then given by:

$$
E_{t}=V_{t} N\left(d_{t}\right)-B_{t} N\left(d_{t}-\sigma \sqrt{T}\right)
$$

where

$$
d_{t}=\frac{\ln \left(V_{t} / B_{t}\right)+\left(\sigma^{2} / 2\right) T}{\sigma \sqrt{T}}
$$

In the market one can observe a time series of equity prices $E_{t}$ and read the face value of bank debt from the balance sheet. With assumptions on the other parameters it is

\footnotetext{
${ }^{7}$ For this class of models it is not necessary to assume that bank assets are traded, just one corporate claim (e.g. equity) has to be traded (?).

${ }^{8}$ see also ?, ?, ?, ?, ?, and ?.

${ }^{9}$ Relaxing this assumption will not dramatically change the results, since the paper's focus is not on deposit insurance pricing. From the available data, I can not determine the amount of uninsured deposits for every bank. Because of this assumption, the strike price of the option is $B_{T}=B_{t} e^{r T}$ and Equation (3) is slightly different than in the classical ? formula.
} 
possible to solve Equation (2) for the market value of the bank's asset portfolio $V_{t}$. I use the maximum likelihood estimator developed by ? and ? to extract the time series of asset values 10 Given a sequence $\mathbf{E}=\left(E_{t}\right), t \in\{1 \ldots m\}$ of equity values, the parameters $(\mu, \sigma)$ of the asset value process in Equation (1) can be estimated by maximizing the following likelihood function:

$$
\begin{aligned}
L(\mathbf{E}, \mu, \sigma)= & -\frac{m-1}{2} \ln (2 \pi)-\frac{m-1}{2} \ln \sigma^{2}-\sum_{t=2}^{m} \ln \hat{V}_{t}(\sigma) \\
& -\sum_{t=2}^{m} \ln \left(N\left(\hat{d}_{t}\right)\right)-\frac{1}{2 \sigma^{2}} \sum_{t=2}^{m}\left[\ln \left(\frac{\hat{V}_{t}(\sigma)}{\hat{V}_{t-1}(\sigma)}\right)-\mu\right]^{2}
\end{aligned}
$$

where $\hat{V}_{t}(\sigma)$ is the solution of Equation (2) with respect to $V$ and $\hat{d}_{t}$ corresponds to $d_{t}$ in Equation (3) with $V_{t}$ replaced by $\hat{V}_{t}(\sigma)$.

For each month in the sample period the parameters of the asset process $\mu$ and $\sigma$ are estimated by assuming the maturity of debt $T$ being equal to one year and using a rolling window similar to ? of monthly market values of total equity $E_{t}$ of the last two years $(m=24) 11$ For a given month I estimate the parameters $\mu$ and $\sigma$ using the last known level of debt and the last 24 observed market values of equity. Then I roll the estimation window forward by one month. The procedure gives parameter sets for every bank and every month in the sample, which can then be used to back out the asset value $\hat{V}_{t}$ for each month. By connecting these over the different years of the sample I get a time series of asset values for all banks over the entire sample period.

\footnotetext{
${ }^{10}$ ? estimate $V$ by first estimating the volatility of equity $\sigma_{E}$. They assume a linear relationship between asset volatility $\sigma$ and $\sigma_{E}$. This together with Equation (2) defines a system of two equations, which can be solved for asset value $V$ and asset volatility $\sigma$. ?, however, points out that $\sigma_{E}$ is stochastic when one assumes a geometric Brownian motion for the asset price process. Therefore $\sigma_{E}$ is hard to estimate and it is not linear in the asset volatility. The maximum likelihood estimator used here overcomes this problem.

${ }^{11}$ The maturity of debt can also be seen as the time until the next audit of the bank, because then the regulator can observe $V$ and close the bank, if it is undercapitalized. In the U.S. the FDIC performs audits every 12 to 18 month. The procedure is also very robust with respect to the size of the estimation window. To check for robustness, I re-estimated all asset values with a window-size of 18 and 36 month. The results do not change.
} 
Table 1: Summary statistics of all banks included in the sample.

\begin{tabular}{lrrrrr}
\multirow{2}{*}{ Region } & Number & \multicolumn{4}{c}{ Total Assets (book values in mill. USD) } \\
\cline { 3 - 6 } & of banks & Sample 1988 & Sample 2002 & $\max (2002)$ & $\min (2002)$ \\
\hline North America & 50 & $1,853,997$ & $4,060,848$ & 693,575 & 11,153 \\
Europe & 40 & $2,091,754$ & $3,726,184$ & 817,557 & 153 \\
Japan & 45 & $4,446,943$ & $1,807,675$ & 814,915 & 12,725 \\
other & 14 & 183,012 & 614,039 & 184,925 & 61 \\
\hline Total & 149 & $8,575,706$ & $10,208,748$ & & \\
\hline
\end{tabular}

\section{Sample}

The sample comprises large international banks included in the GlobalVantage database. Equity prices are recorded on a monthly basis from January 1986 until December 2002 and balance sheet information is collected annually starting 1988 .

From all banks recorded in GlobalVantage, I include the largest 149 banks (based on book values of total assets in 1988) for which balance sheet as well as market information are available. Total assets (book values) of all banks increase only modestly during the sample period. The largest bank in the sample - Deutsche Bank - has assets of USD 817 billion, the smallest bank has USD 61 million, and the median bank size is USD 14.3 billion. Banks are grouped in different regions: North America (U.S. and Canada), Europe (E.U. countries, Switzerland, and Norway), Japan and other countries. Table 1] shows summary information for different regions. To avoid survivorship bias, merged or bankrupt banks are included in the sample as long as balance sheet information is available. Appendix $\mathrm{A}$ contains additional summary statistics of bank accounting variables used in the subsequent analysis.

\section{Dynamics of bank asset values}

With the methodology explained in Section 2, it is possible to extract a time series of market values of bank assets. The three key input variables for the measures of systemic 
risk are asset correlations, asset volatilities and bank capitalization, which are explored in this section. To measure the correlations and volatilities of the banks' portfolios, for each month in the sample period a variance-covariance matrix $\Sigma_{t}$ of the asset-returns is estimated using a simple exponentially weighted moving average (EWMA) model with a decay factor $\lambda$ of 0.9412 The covariance $\sigma_{i j, t}$ at time $t$ between the asset portfolios of bank $i$ and $j$ are estimated by

$$
\sigma_{i j, t}=\lambda \sigma_{i j, t-1}+(1-\lambda) \ln \left(\frac{V_{t}^{i}}{V_{t-1}^{i}}\right) \ln \left(\frac{V_{t}^{j}}{V_{t-1}^{j}}\right)
$$

Figure 1 plots the correlations between bank asset portfolios over the sample period 13 The asset correlations give superior information compared to equity correlations as they are not influenced by changes in the capital structure. For the whole sample median correlations are positive for the whole time period. Surprisingly they are very stable over time, even though regulators have raised concerns about correlations more frequently in the last couple of years. The only two sharp increases in median correlations are in August 1990, at the time of the Iraqi Invasion in Kuwait, and in August/September 1998 when Russia defaulted and Long Term Capital Management (LTCM) nearly collapsed.

Compared to the banks in the North American as well as the Japanese sub-sample, European banks are more diversified as their median correlation is much lower, which

\footnotetext{
${ }^{12}$ The EWMA model was chosen because it is used in the RiskMetrics framework, which is a standard in market risk management. Since the time series is relatively short, it is hard to evaluate alternative volatility models and identify the best fitting one. For this reason the decay factor was also chosen as in the RiskMetrics set-up. Following the RiskMetrics specification I also neglect the mean return. The mean return for the asset portfolio is quite small, on average 0.00011 for the whole sample and 0.00034 for North America, where bank asset values increased most. Including the mean does not significantly change results. For robustness a simple equally weighted 24 month moving average was also tested but the results were very similar. One could also use the estimate $\sigma$ from equation (44) for bank volatility. This volatility is equal to a simple moving average (over the last 24 month) if one would fix the parameter estimates $\mu$ and $\sigma$. I did not use this measure for two reasons: first, it corresponds to the simple average, and the results of the simple average are similar to the EWMA model. Second, the EWMA model puts more weight on more recent observations and is therefore more capable of capturing changes in risk levels.

${ }^{13}$ Correlations in market values of liabilities do not have to considered here. The focus of correlations of asset values is consistent with the theoretical assumptions of the model, as default is assumed to occur when the market value of the bank's assets is below the face value of the liabilities (which are assumed to be fixed).
} 
Figure 1: Monthly correlation estimates between banks for the whole sample and the different sub-samples from Jan. 1988 until Dec. 2002. From all pair wise correlations (there are 11026 correlations for the 149 banks in the whole sample), the median correlation as well as the $10 \%$ and the $90 \%$ quantile are shown.

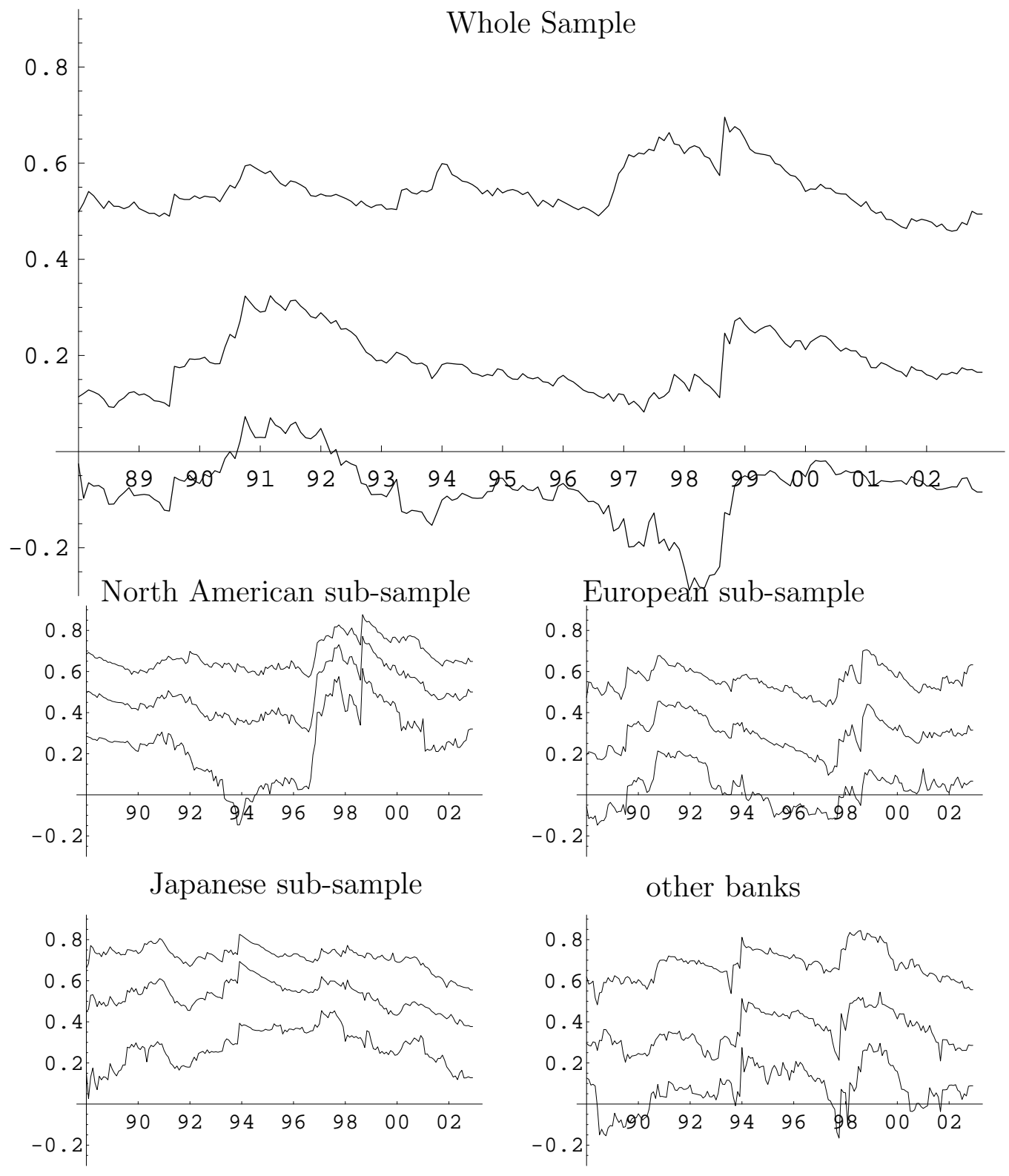


could reflect the fact that European financial markets are not that integrated yet and that banks are subject to different national regulatory standards. Very notable is the substantial increase in correlations in the North American banking sector. Starting in fall 1996 correlations increased substantially and stayed at a higher level. This result is consistent with the study of ?, who analyze equity correlations of large US banks. Correlations in Japan were - surprisingly - not affected by the Asian crisis. The sub-sample "other banks" includes banks from Latin America, Asia, Australia and Eastern Europe. Considering the geographic diversification it is surprising that median correlations are so high. It is also interesting to note what events did not affect correlations: The crisis and subsequent wars in Yugoslavia, the collapse of the Soviet Union (1991), the Peso Crisis (Dec. 1994), and the Earthquake in Kobe (Jan. 1995) and the subsequent failure of Barings bank.

To confirm the intuition from the graphs I estimate a fixed effects regression explaining the median correlation of a bank to all other banks (Corr) as well as the median correlation of a bank to the banks in the same region (regional Corr). The explanatory variables are time trends for the three regions, dummies for the time after 1997 (to capture the Asian crisis) as well as bank specific factors: bank size (SIZE) measured as logarithm of total assets as larger banks may be active in more markets and face better possibilities for diversification, the ratio of book value of equity to total assets (EQBK) as banks with a higher capital cushion may be able to invest in riskier assets, the return on assets (ROA), and the fraction of long term debt to total debt (LTDEBT) as a measure of liquidity 14 Due to data limitations in GlobalVantage the number of observations decreases to 1,254. The results are shown in Table $2{ }^{15}$ Correlations de-

\footnotetext{
${ }^{14}$ I include these bank specific variables to control for factors that are not included in the theoretical model. The bank specific variables may also be of interest for the regulator as they allow identifying banks with higher systemic risk based on accounting variables, but this is not the purpose of this paper. To check for robustness I extended the set of explanatory variables by provisions for loan losses as a measure for risk and quality of the loan portfolio, subordinated debt as a measure of exposure to market discipline, and cash as a measure of liquidity. Due to data limitations, the sample size is reduced dramatically, but the main results still hold. The tables are available from the author upon request.

${ }^{15}$ To check for robustness, I also estimate the regressions in Table 2 separately for each sub-sample. The main results of the paper are confirmed. For brevity the tables are not included in the paper but are available from the author upon request.
} 
cline significantly only in Japan. Global bank correlations increase after 1997, especially for North American and somewhat for European banks. With respect to the regional banks, correlations increased after 1997 for all banks but especially for North American banks. Larger banks tend to hold more correlated portfolios.

Analyzing the volatilities of the banks' asset portfolios, we can see in Table 2 increasing volatilities for North American Banks and decreasing volatilities for Japanese banks. With respect to the Asian Crisis, I find a positive jump in volatilities after 1997 for North America and Japan, with Japanese banks facing the largest increase. Bank characteristics have some explanatory power for changes in bank volatilities. After bank specific fixed effects, larger and well-capitalized banks (in book value terms) invest in riskier assets, while banks that are more profitable reduce their asset volatility 16

The financial soundness of the banking sector is analyzed using the median capitalization ratio, which is measured as market value of assets $V$ over face value of debt $B$. The results in Table 2 show a dramatic increase in North American bank capitalization after 1997 and a loss for Japanese banks. This increase is also in line with the results of ?, who report that banks have increased the capital ratio in market as well as in book value terms. European banks have also enhanced their capital base over time but not as high as the American banks. We can also see that larger banks and more profitable banks are better capitalized.

To summarize, North American banks have the highest capitalization ratios, but show in the median higher volatility and correlations than the European banks. The European banks have less correlated portfolios than their American and Japanese counterparts. The main problem of the Japanese banks in the sample is the poor capitalization ratio.

Several alternative model specifications could be used instead of the simple Merton framework to check for robustness. ? estimate market values of asset portfolios as well as asset volatilities for four alternative specifications (two single period and two infinite horizon models). They find, however, that correlations of $B / V$ estimated by the

\footnotetext{
${ }^{16}$ Graphs similar to Figure 1 are available from the authors on request.
} 
Table 2: Results from a fixed effects panel regression (corrected for an AR(1) disturbance) explaining the median correlation of a bank's asset portfolio with the portfolios of all other banks (Corr.), the median correlation of a bank's asset portfolio with the portfolios of all other banks in the same region (regional Corr.), the volatility of a bank's assets (Volatility), and the bank's capitalization ratio $V / B$ (Capitalization). The explanatory variables are time trends (TIMEUS, TIMEEU, TIMEJP), dummy variables for the impact of the Asian crisis which are set to unity after 1997 (DUM97US, DUM97EU, DUM97JP), bank size (SIZE) measured as logarithm of total assets, the return on assets (ROA), book value capitalization (EQBK) measured as book value of equity over total assets, and the ratio of long term debt (with maturity greater than one year) over total debt (LTDEBT). Capitalization is not regressed on EQBK to avoid a possible problem of endogenous variables. Variables with ${ }^{*}$ and ${ }^{* *}$ are significant at the $5 \%$ and $1 \%$ level respectively.

\begin{tabular}{lcccc} 
& Corr. & regional Corr. & Volatility & Capitalization \\
\hline $\mathrm{N}$ & 1254 & 1254 & 1254 & 1254 \\
$R^{2}$ & 0.0920 & 0.1484 & 0.1808 & 0.1693 \\
\hline TIMEUS & -0.0050 & -0.0043 & $0.0007^{* *}$ & $-0.0106^{* *}$ \\
& $(-1.50)$ & $(-1.05)$ & $(3.83)$ & $(-3.16)$ \\
TIMEEU & -0.0062 & -0.0074 & $0.0004^{*}$ & 0.0001 \\
& $(-1.74)$ & $(-1.67)$ & $(2.08)$ & $(0.04)$ \\
TIMEJP & $-0.0106^{* *}$ & $-0.0236^{* *}$ & $-0.0008^{* *}$ & 0.0024 \\
& $(-3.63)$ & $(-6.52)$ & $(-4.78)$ & $(0.82)$ \\
DUM97US & $0.1251^{* *}$ & $0.1390^{* *}$ & $0.0016^{*}$ & $0.1358^{* *}$ \\
& $(7.41)$ & $(6.51)$ & $(2.14)$ & $(6.81)$ \\
DUM97EU & $0.0588^{* *}$ & $0.0969^{* *}$ & 0.0007 & 0.0340 \\
& $(3.28)$ & $(4.27)$ & $(0.91)$ & $(1.60)$ \\
DUM97JP & 0.0241 & $0.0389^{*}$ & $0.0049^{* *}$ & $-0.0359^{*}$ \\
& $(1.59)$ & $(2.03)$ & $(7.21)$ & $(-1.99)$ \\
SIZE & 0.0058 & $0.0426^{* *}$ & $0.0022^{* *}$ & $0.0413^{* *}$ \\
& $(0.63)$ & $(3.67)$ & $(4.64)$ & $(3.73)$ \\
ROA & -0.0024 & -0.0003 & $-0.0007^{* *}$ & $0.0355^{* *}$ \\
& $(-0.74)$ & $(-0.08)$ & $(-5.00)$ & $(9.28)$ \\
EQBK & 0.0526 & 0.2156 & $0.1124^{* *}$ & \\
LTDEBT & $(0.32)$ & $(1.03)$ & $(14.28)$ & \\
& -0.0110 & -0.0251 & $0.0089^{* *}$ & 0.1061 \\
& $(-0.19)$ & $(-0.35)$ & $(3.23)$ & $(1.75)$ \\
\hline
\end{tabular}


different models are between 0.964 and 0.998 and those of asset volatility between 0.836 and 0.998. It is therefore doubtful, whether alternative model specification would yield economically significant different results.

A possible problem with the methodology presented here is that pure movements of the stock market could affect the increase or decrease in bank capitalization. In a recent study ? find that only $21 \%$ of the increase in U.S. bank capitalization in the 1990s is attributable to the stock market. Using a different technique than in this paper, they find that banks have increased their capital ratio as answer to an increase of the risk in their portfolios 17

Efficient information processing by stock markets, especially on the interdependencies between banks, is also crucial to the methodology of this paper. A broad stream of previous literature shows that the market is able to assess how new information on one bank affects rival banks' share prices. ? look at the three largest bank failures before 1980 finding no impact on other bank stocks when the cause of the failure is idiosyncratic (e.g. fraud), whereas adverse information on problems that might be shared by other banks cause other banks' share prices to decline. Analyzing dividend reduction announcements and regulatory enforcement actions ? find negative reactions to dividend reduction announcements of money center banks. Dividend cuts and regulatory enforcement actions against regional banks have a positive effect on rival banks 18

\footnotetext{
${ }^{17}$ The advantage of this approach is that it uses the information incorporated into market prices. The assumption of the model is that share prices move together with asset values assuming a rational market. Alternatively one could argue that stock price movements are just random fluctuations or that the stock market is over- or undervalued at times. It is very hard to control for these problems because it is hard to disentangle upward movements because of good economic conditions from irrational overpricing. While using book values solves the problems mentioned above, one also loses the informational advantage of market prices.

${ }^{18}$ ? applies the same methodology to the failure of Continental Illinois Bank in 1983-84 and finds significant negative returns especially for banks with a large amount of Latin American debt and other bad loans. ? find a significant negative market reaction on British bank shares after a USD 3 billion loan loss announcement of Citicorp. ? find negative stock market returns following loan loss announcements of regional banks while they find no negative market reaction to loan loss announcements of money center banks, suggesting that this information is already anticipated by the market. Also notable are the studies of ? or ?, who explore the effect of yield spreads for bank debt after failures of other banks and of ?, who relate the size of the contagion effect to bank characteristics.
} 


\section{Measures of systemic risk}

A systemic crisis can be defined as an event in which a considerable number of financial institutions default simultaneously. Several indicators of systemic risk can be specified, once the joint dynamics of bank asset portfolios are estimated.

\subsection{Probability of a systemic crisis}

A clear threshold when individual bank failures become a systemic crisis can not be defined. One possibility is to compute the probability that banks with total assets of more than a certain percentage $\xi$ of all bank assets go bankrupt within a short period of time. A bank is assumed to be bankrupt if the market value of the assets falls below the face value of its debt within the next six month 19

Define the systemic risk index based on assets $S I V(\xi)$ as this probability. Formally, let $\mathcal{I}$ be the index set numbering individual banks. Then a systemic event based on assets $s v$ is defined by

$$
s v: V_{t+1}^{j}<B_{t+1}^{j} \forall j \in \mathcal{J} \subset \mathcal{I}, \sum_{j \in \mathcal{J}} V_{t}^{j}>\xi \sum_{i \in \mathcal{I}} V_{t}^{i}
$$

Define $\mathcal{S}_{V}$ as the set of all $s v$ and let $\mathbb{P}$ be the associated probability measure, then

$$
S I V(\xi)=\mathbb{P}\left(\mathcal{S}_{V}\right)
$$

The systemic risk index is obtained using Monte Carlo simulation. The simulation is run for every month of the sample period. In each of the two million runs of each monthly simulation, the joint process of all banks' asset values is simulated with a time horizon of six months using a Cholesky-decomposition of the variance-covariance matrix. The

\footnotetext{
${ }^{19}$ The time horizon will clearly affect the level of the risk systemic risk indicators that are presented in this section. Rather that looking at levels, the main idea behind the systemic risk measures is to serve as an indicator of systemic risk that can be compared with other countries as well as over time. These comparisons should not be affected by the time horizon.
} 
details of the simulation can be found in Appendix B. For each scenario it is evaluated whether the bankrupt banks have assets that exceed the specified fraction of all banks' assets.

Figure 2 shows the time series for the SIV index from Jan. 1988 until Dec. 2002 for the North American, the European and the Japanese sub-samples, respectively. There was substantial risk in the US banking system in the late 1980s and early 1990s, peaks can be seen at the invasion of Kuwait (August 1990) and at the disruption of the Soviet Union (Soviet tanks shot at the Russian parliament, in August 1991). After that, systemic risk in North America vanished. The European Banking system is quite stable. The British withdrawal from the European Currency System following a devaluation of the Pound caused adverse effects for the European banking system around September 1992. While the Japanese Banking system had been very stable for a long period in time, it was hit by the decline in asset values during 1997/98, which caused an substantial increase in systemic risk. The increase in systemic risk in the Japanese banking sector started as early as March 1997 and systemic risk stays high after November 1997, when Sanyo securities defaulted in the inter-bank market which had never happened before in Japan (see ? for a detailed history of events).

The $S I V$ index as a measure for systemic risk is driven by the very large banks. A ceteris paribus increase in the value of the assets or the asset risk of one of the large banks will directly affect this measure of risk. Alternatively, regulators may also be concerned that more than a certain fraction of financial institutions in the banking system become insolvent at the same time. This index is the polar case to the asset based systemic risk index as this probability is independent of the size distribution in the banking sector. Define the systemic risk index based on number of banks $S I N(\phi)$ as the probability that more than a certain fraction $\phi$ of banks will go bankrupt at the same time. Formally define $s n$ as such an event:

$$
\text { sn }: V_{t+1}^{j}<B_{t+1}^{j} \forall j \in \mathcal{J} \subset \mathcal{I}, \# \mathcal{J}>\phi \# \mathcal{I}
$$


Figure 2: Probability that banks with total assets of more than 5\%, $10 \%$ and $20 \%$ of all assets held by banks go bankrupt within the next six month $(S I V)$, where bankruptcy is assumed to occur, when the market value of the assets is below the face value of debt. Probabilities are estimated monthly from Jan. 1988 until Dec. 2002 and are shown for the North American, the European and the Japanese sub-samples respectively.
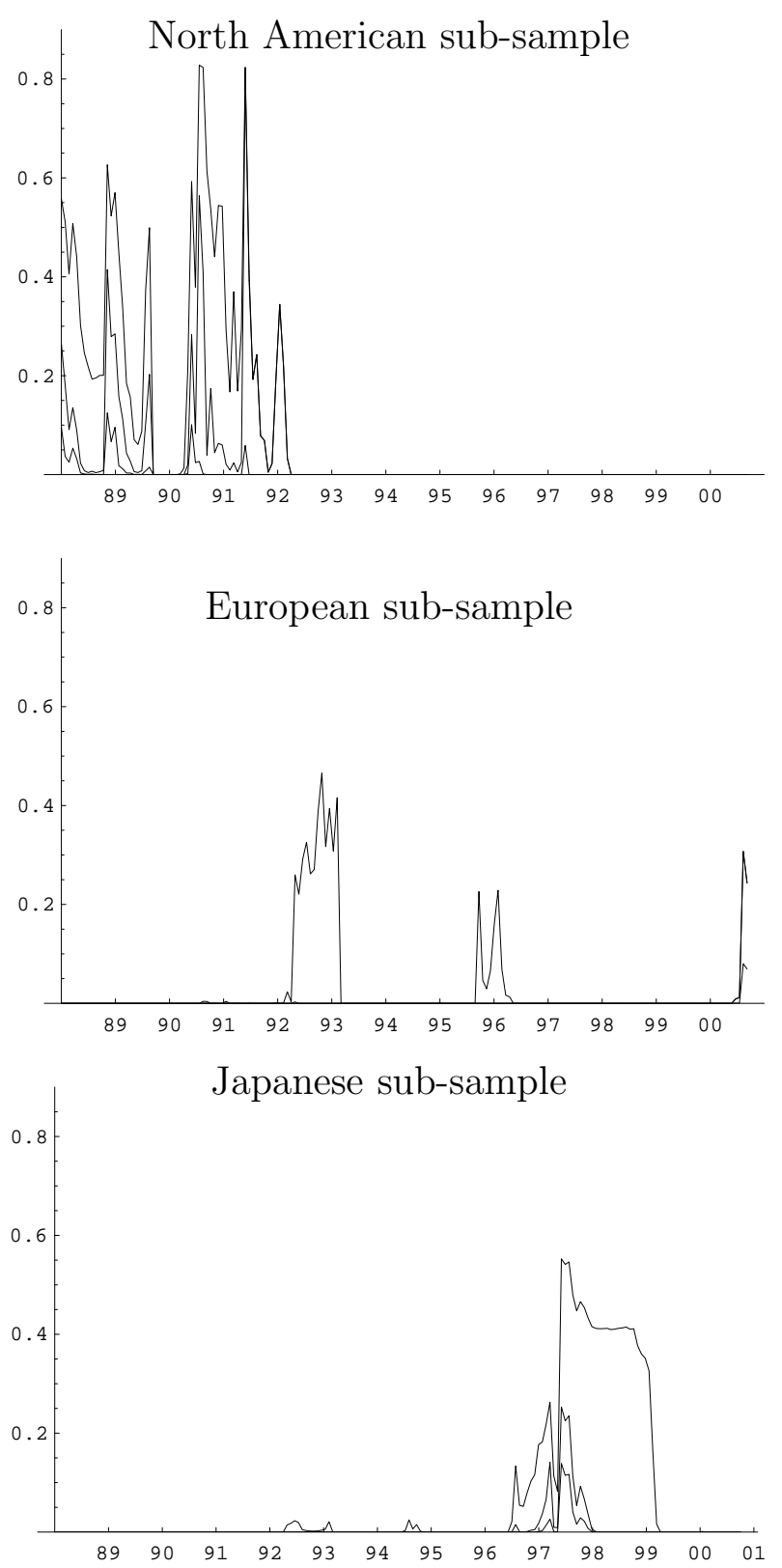
and define $\mathcal{S}_{n}$ as the set of all $s n$ then

$$
S I N(\phi)=\mathbb{P}\left(\mathcal{S}_{n}\right)
$$

Figure 3 shows the probability that more than a certain threshold number of banks will default. The pattern is very similar to the previous figure for the North American and the Japanese Banks. One can again see an increase in the probability of multiple bank defaults in the Japanese sub-sample during the period of $1997 / 98$. However, the situation is quite different for Europe where multiple bank failures are more likely. This can only be explained by the fact that smaller banks are either riskier or tend to hold higher correlated assets 20

\subsection{Robustness Considerations}

It is - unfortunately - very hard to verify the results empirically by means of a statistical test. While one could in principle apply standard tests for market risk management models, there are two problems in this setting. First we only have 180 monthly observations for each sub-sample, which is not enough to get statistically reliable results.21 Second for most countries, no data is available on actual bank failures and bank interventions by the regulator. While no statistical verification, Figure 4 shows the probability that banks with more than $5 \%$ of North American banks' assets go bankrupt within the next six month (forward looking) and the actual - ex post - fraction of failed banks with FDIC coverage in the U.S. over that horizon 22 The correlation is quite remarkable given that the two numbers are not probabilities (or realizations) of the same event and considering the fact that only 50 banks are used to compute the systemic risk index for the U.S.

\footnotetext{
${ }^{20}$ State guarantees that are very common in Europe are unlikely to affect results as they are almost exclusively granted to non-listed mutual savings institutions, which are not in the sample.

${ }^{21}$ The minimum number of observations for verification of bank-internal risk management models recommended by the Basle Committee on Banking Supervision is 250. However even then the tests are of low statistical power (see ?).

${ }^{22}$ The FDIC data was collected from FDIC annual reports.
} 
Figure 3: Probability that more than 5\%,10\% and $20 \%$ of all banks go bankrupt within the next six month $(S I N)$. Probabilities are estimated monthly from Jan. 1988 until Dec. 2002 and are shown for the North American, the European and the Japanese subsamples respectively.
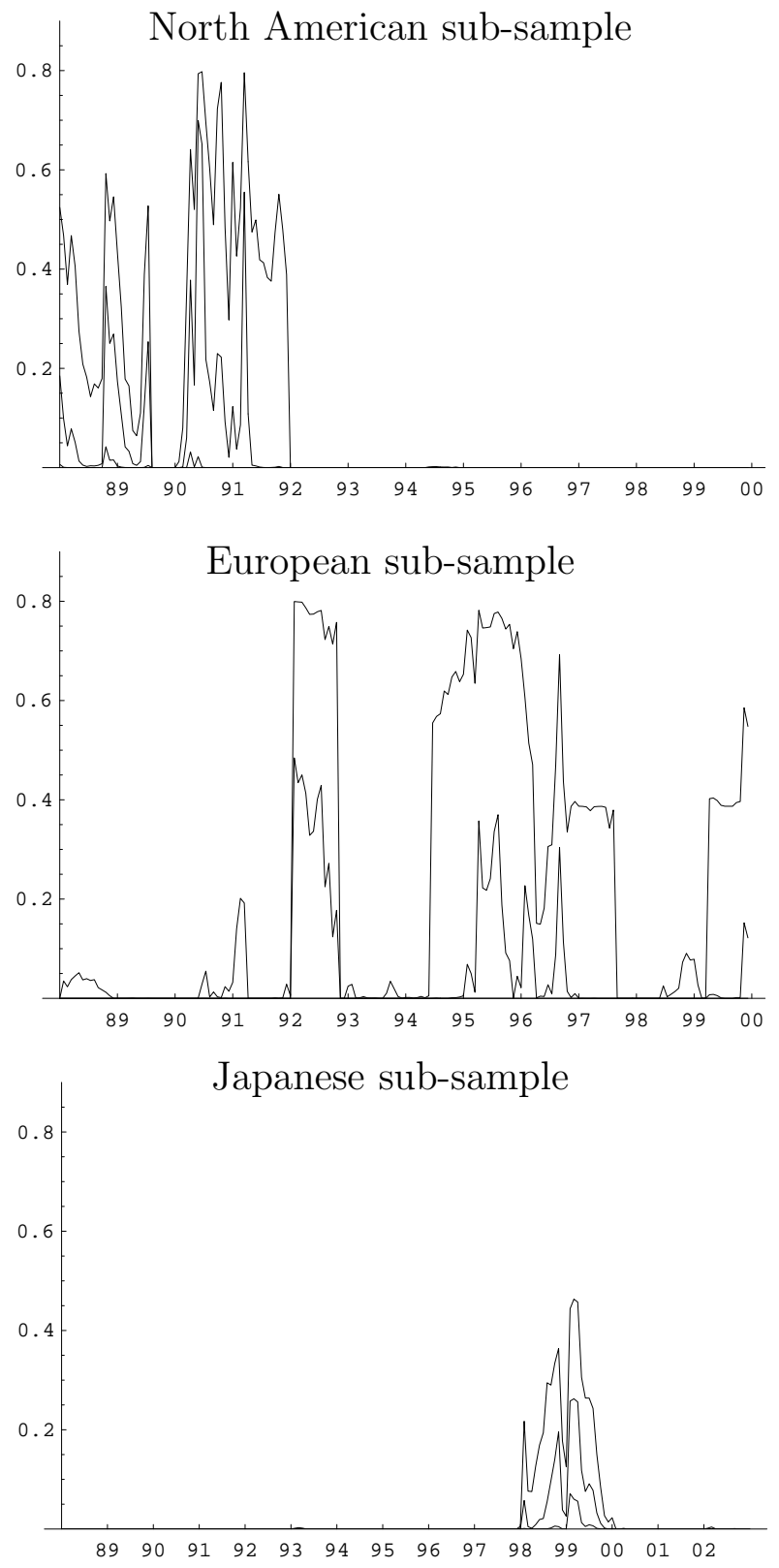
Figure 4: Probability that banks with more than 5\% of North American banks' assets go bankrupt within the next six month (gray line, left axis) and actual fraction of U.S. banks with FDIC coverage that went bankrupt in the following six month (black line, right axis)

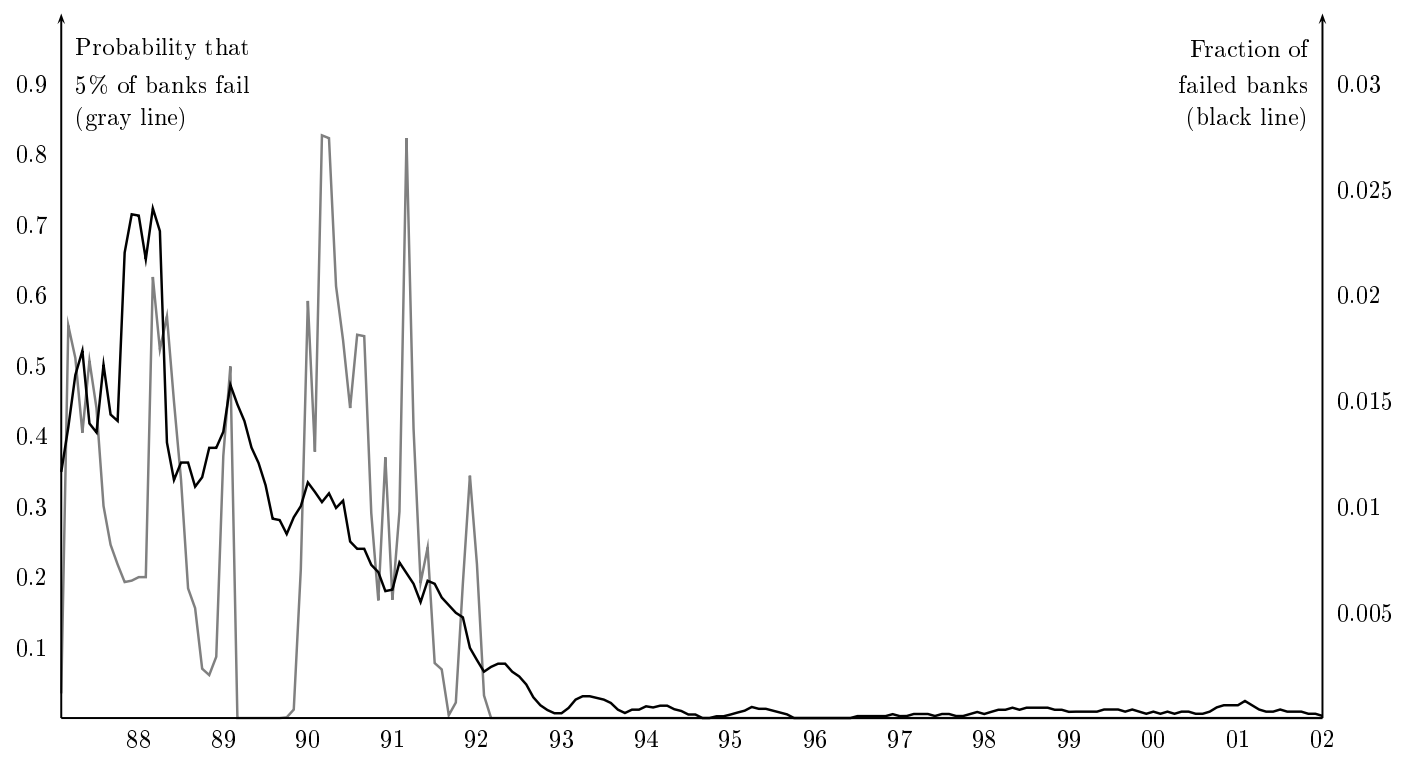

and Canada, while e.g. in 1988 there were 16,575 financial institutions with FDIC coverage in the U.S. alone. The systemic risk index, which is based on market information, often anticipates trends in subsequent failures. This is consistent with the findings of ? who show that default probabilities extracted from equity market information anticipate changes in supervisory ratings for up to four quarters.

In line with the standard risk management literature, I assume throughout the paper that the returns on the banks' asset portfolios are normally distributed. One could consider alternative distributions to include frequently observed characteristics of equity return series like fat tails. However, this would be inconsistent with the assumptions of the estimation procedure in Equation 4 and the assumed dynamics of asset values in Equation 1 13 Another potential problem when computing the systemic risk indices is numerical accuracy. Appendix C reports the results from a simulation study, which

\footnotetext{
${ }^{23}$ Note that normality is assumed for the asset values. The equity values, where most studies document skewness and kurtosis, are not normally distributed in this setting.
} 
shows that the number of runs in the simulation is high enough to give results with reasonable precision 24

\subsection{Expected shortfall}

From a regulator's perspective it may not be relevant just to look at default probabilities, but also at the expected shortfall, which is the present value of the amount of debt that can not be covered by the assets of the bank in case of default (i.e. $\max (B-V, 0))$. In the simple ? framework, this is given by the value of a put option. If all the debt is insured then the expected shortfall is equal to the future liability of the deposit insurance, as the regulator must pay the difference between the face value of deposits and the proceeds from selling the banks assets at the market value 25 Previous studies such as ? or ? use the same methodology to compute the value of the deposit insurance liability. Formally I compute the expected shortfall $S_{t}^{i}$ of bank $i$ at time $t$ for a horizon of $T$ years as the value of a put option

$$
S_{t}^{i}=B_{t}^{i} N\left(-d_{t}+\sigma \sqrt{T}\right)-V_{t}^{i} N\left(-d_{t}\right)
$$

where $B_{t}^{i}$ is the face value of the bank's debt, $V_{t}^{i}$ is the market values of the asset portfolio, and $d_{t}$ is defined as in Equation (3). The expected shortfall for all banks in the sample is therefore $S_{t}=\sum_{i} S_{t}^{i}$. This measure will inform the deposit insurance agency of the value of its liabilities and the bank regulator on the systemic risk in banking system. Figure 5 shows this future liability for all banks over the whole sample period. The expected shortfall varies considerably over time as one would expect after looking at the time variations in bank asset volatility and in bank capitalization. The peak in 1998 is again attributable to the Asian crisis.

Because of this variation, the regulator might not only be concerned about the level

\footnotetext{
${ }^{24}$ The optimal number of simulation runs has to be determined by balancing accuracy against a feasible computation time. The appendix shows, that 2 million runs give a reasonable precision and that increasing the number of runs to 4 million will not decrease standard errors dramatically.

${ }^{25}$ If part of the bank's deposits are not insured, this measure will overestimate the risk to the deposit insurer.
} 
Figure 5: The present value of the regulator's expected shortfall for a holding horizon of one year plotted from Jan. 1988 until Dec. 2002 (in million USD).

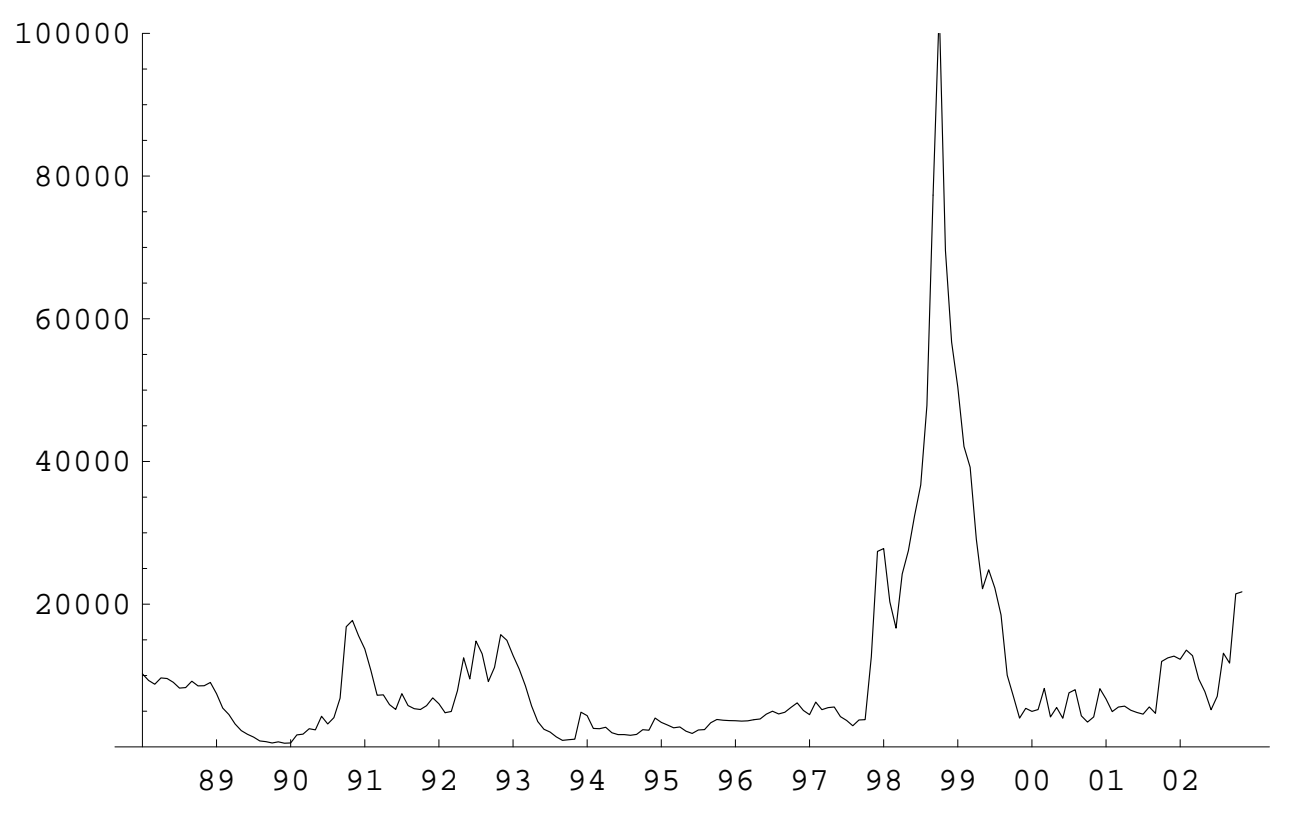

of the expected shortfall but also about its dynamics. In an economy with uncorrelated bank portfolios a shock to the assets of one bank will increase the regulator's liability towards this bank directly but it will not affect costs due to failures of other banks. In a low correlation banking system, in which the shocks to the bank asset portfolios are mainly idiosyncratic, the volatility in the regulator's portfolio of expected shortfall should therefore be low. With highly correlated asset portfolios a shock will again hit the regulator directly but will also adversely affect the liabilities towards other banks. Thus, high systemic risk in the banking system will imply high volatility of expected shortfall. It is thus important to look at the liability of the deposit insurance agency and at the potential future shortfall in a banking system from a portfolio perspective and not just at the level of individual banks. The regulator's portfolio can be defined at multiple levels. Deposit insurers and national regulators can apply the methodology of this section to the banks under their supervision. Supra-national institutions like the European Central Bank, the IMF or the BIS may want to include banks from several countries in their analysis. In this paper I compute all measures for a world wide portfolio. 
When we look at the insurer's exposure, we have a portfolio of put options written on the individual banks' asset portfolios. We can then use standard methods from the risk management literature (see, e.g., ?) to compute the volatility of the expected shortfall in the banking sector. Let $\Sigma_{t}$ be the variance-covariance matrix of the returns on the banks' asset portfolios, and $\delta_{t}$ the vector of partial derivatives $\left(V_{t}^{i} \partial S_{t}^{i} / \partial V_{t}^{i}\right)$. Then, using first order terms, the Dollar-volatility of the expected shortfall $z_{t}$ can be approximated by 26 :

$$
z_{t}=\sqrt{\delta_{t} \Sigma_{t} \delta_{t}^{\prime}}
$$

To break down the contribution of an individual bank or a group of banks to the regulator's risk exposure, I decompose the volatility of the expected shortfall using the standard concept of component value at risk 27 Define

$$
\zeta_{t}=\frac{1}{z_{t}}\left(\Sigma_{t} \delta_{t}^{\prime}\right) * \delta_{t}^{\prime}
$$

as the vector of contributions to the expected shortfall risk, where $*$ is the elementwise product of two vectors. Due to the nice property that the sum of the elements of $\zeta_{t}$ is equal to $z_{t}$, the elements of this vector are the contributions of individual banks to the overall volatility in expected shortfall. These contributions can also be negative, when a bank reduces the risk of the regulator's portfolio.

Figure 6] shows the volatility of the regulator's expected shortfall in percent 28 The volatility is very high (in general above 40\%), which is due to the fact that the regulator's portfolio consists of out of the money put options that are very sensitive to changes in the underlying (i.e. the value of a bank's asset portfolio). North American banks contribute little to the overall risk up to the year 2000. The Japanese banks in the sample, which are the worst capitalized on average, have the highest contribution to the regulator's risk.

\footnotetext{
${ }^{26}$ By taking into account second order effects (Gamma), the accuracy of the value-at-risk estimation could be enhanced. The simpler method used in this section is used because it allows us to compute the contribution of each bank to the value-at-risk, which is used in the subsequent analysis.

${ }^{27}$ see e.g. ? p. 159.

${ }^{28}$ i.e. the graph shows $\frac{z_{t}}{S_{t}}$ for the whole sample and $\frac{\sum_{j \in \mathcal{J}} \zeta_{t}^{j}}{S_{t}}$ for the subset of banks in sub-sample $\mathcal{J}$.
} 
The group of "other banks" can explain only a small portion of the overall volatility because of the small size of this sub-sample.

To perform an econometric analysis of volatility contributions which includes bank characteristics, it is useful to standardize regulatory risk by a bank specific variable, which is quite stable over time. Since deposit insurance premiums are often expressed per dollar of insured deposits, the liabilities of the bank are a natural candidate to standardize the risk of the deposit insurer as well. Table 3 shows the results from a panel regression of $\zeta_{t}^{i} / B_{t}^{i}$ on a time trend, dummy variables for the impact of the Asian crisis after 1997 for the three economies as well as bank specific variables. I include bank specific fixed effects because the risk that a specific bank contributes can also be influenced by factors such as the location of the bank, the local regulator's policies, accounting and auditing standards or listing requirements. The bank specific explanatory variables are defined as in Section 4 .

In line with the graphs, we can see an economically and statistically significant jump in the risk of Japanese banks after 1997. Banks that are more profitable are less risky for the regulator. Surprisingly, book value of equity capital, the prime instrument of bank regulation, has no significant impact on the risk contributions of a bank to the global regulator's portfolio. To analyze the effectiveness of capital requirements, I collect the bank's regulatory tier-2 capitalization ratio, which is available for a subset of 1,164 observations. This ratio is defined as regulatory capital over risk adjusted assets and differs from the EQBK ratio because of different definitions of equity capital in the nominator and the weighting of assets with different risk weights in the denominator. The minimum regulatory capital level of banks is set at $8 \%$ in most countries. I divide the sample into banks with regulatory capital levels below 10\%, which are under more regulatory pressure since they are close to the minimum and into well capitalized banks with no constraints ${ }^{29}$ Capital requirements make a lot of sense to confine systemic risk

\footnotetext{
${ }^{29}$ In the U.S. bank regulators also use a $10 \%$ cutoff level to distinguish between "well capitalized" banks and "adequately capitalized" banks under the Federal Deposit Insurance Corporation Improvement Act (FDICIA) of 1991.
} 
Figure 6: Volatility p.a. of the regulator's deposit insurance liability from Jan. 1988 until Dec. 2002. The graphs of the four sub-samples show the volatility contributions of each sub-sample to the portfolio volatility. The banks in the Japanese and the European subsample contribute most to the variation in the regulator's risk while the North American banking sector is very stable.
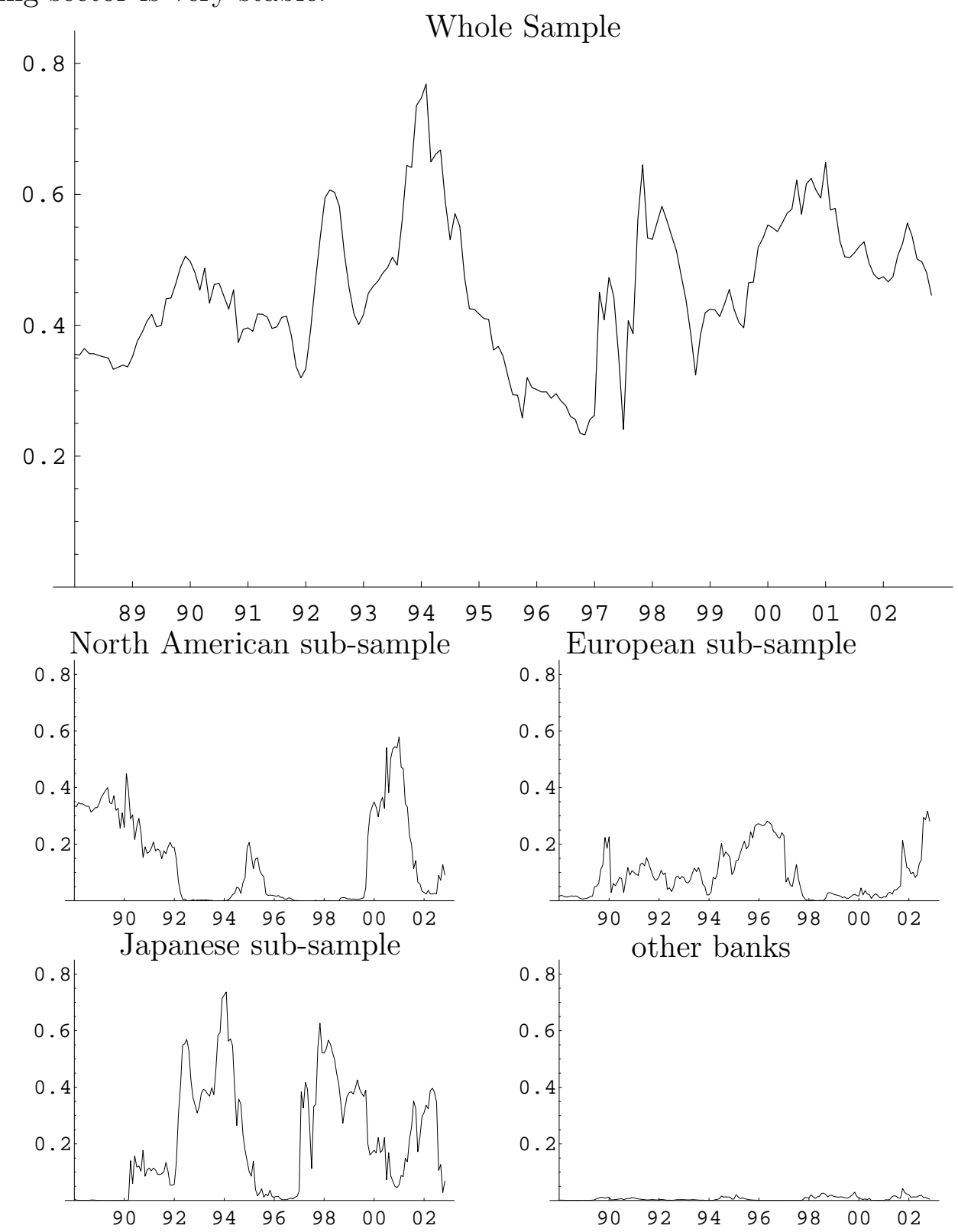
Table 3: Results from a fixed effects panel regression (corrected for an AR(1) disturbance) explaining the contribution of an individual bank to the risk of a global deposit insurers portfolio $(\zeta)$ standardized by the bank's liabilities $(B)$. In the last two columns the sample is split into banks under regulatory pressure (regulatory capitalization ratio below 10\%) and into well capitalized banks. The explanatory variables are time trends, dummy variables for the impact of the Asian crisis which are set to unity after 1997, bank size (SIZE) measured as logarithm of total assets, return on assets (ROA), book value capitalization (EQBK) measured as book value of equity over total assets, and the ratio of long term debt over total debt (LTDEBT). Variables with $*$ and $* *$ are significant at the $5 \%$ and $1 \%$ level respectively.

\begin{tabular}{|c|c|c|c|c|c|}
\hline & $\begin{array}{r}\text { all banks } \\
\zeta_{t}^{i} / B_{t}^{i}\end{array}$ & $\begin{array}{r}\text { all banks } \\
\zeta_{t}^{i} / B_{t}^{i} \\
\end{array}$ & $\begin{array}{r}\text { all banks } \\
\zeta_{t}^{i} / B_{t}^{i} \\
\end{array}$ & $\begin{array}{r}\text { pressured } \\
\zeta_{t}^{i} / B_{t}^{i} \\
\end{array}$ & $\begin{array}{r}\text { well capitalzed } \\
\qquad \zeta_{t}^{i} / B_{t}^{i}\end{array}$ \\
\hline $\bar{N}$ & 1254 & 1254 & 1254 & 247 & 917 \\
\hline$R^{2}$ & 0.1837 & 0.0700 & 0.0943 & 0.1435 & 0.0740 \\
\hline TIMEUS & $\begin{array}{l}0.0079 \\
(1.04)\end{array}$ & & $\begin{array}{r}-0.0036 \\
(-0.68)\end{array}$ & & \\
\hline TIMEEU & $\begin{array}{r}0.0124 \\
(1.52)\end{array}$ & & $\begin{array}{r}0.0052 \\
(0.94)\end{array}$ & & \\
\hline TIMEJP & $\begin{array}{c}-0.0540^{* *} \\
(-8.14)\end{array}$ & & $\begin{array}{l}-0.0313^{* *} \\
(-6.36)\end{array}$ & & \\
\hline DUM97US & $\begin{array}{r}0.0070 \\
(0.16)\end{array}$ & & $\begin{array}{r}0.0306 \\
(0.77)\end{array}$ & & \\
\hline DUM97EU & $\begin{array}{r}-0.0834 \\
(-1.78)\end{array}$ & & $\begin{array}{r}-0.0627 \\
(-1.54)\end{array}$ & & \\
\hline DUM97JP & $\begin{array}{l}0.4741^{* *} \\
(11.97)\end{array}$ & & $\begin{array}{l}0.4072^{* *} \\
(11.57)\end{array}$ & & \\
\hline SIZE & $\begin{array}{r}-0.0167 \\
(-0.69)\end{array}$ & $\begin{array}{r}-0.0118 \\
(-0.57)\end{array}$ & & $\begin{array}{r}0.0235 \\
(1.34)\end{array}$ & $\begin{array}{l}0.0269^{* *} \\
(2.64)\end{array}$ \\
\hline $\mathrm{ROA}$ & $\begin{array}{c}-0.0701^{* *} \\
(-8.24)\end{array}$ & $\begin{array}{c}-0.0778^{* *} \\
(-8.69)\end{array}$ & & $\begin{array}{c}-0.0919^{*} \\
(-2.60)\end{array}$ & $\begin{array}{c}-0.0663^{* *} \\
(-7.18)\end{array}$ \\
\hline EQBK & $\begin{array}{r}0.4457 \\
(1.06)\end{array}$ & $\begin{array}{r}0.5581 \\
(1.25)\end{array}$ & & $\begin{array}{c}-6.4069^{*} \\
(-2.07)\end{array}$ & $\begin{array}{r}0.7345 \\
(1.59)\end{array}$ \\
\hline LTDEBT & $\begin{array}{r}0.1435 \\
(1.06)\end{array}$ & $\begin{array}{r}0.2361 \\
(1.65)\end{array}$ & & $\begin{array}{c}1.0436^{*} \\
(2.49)\end{array}$ & $\begin{array}{r}0.1214 \\
(0.72)\end{array}$ \\
\hline
\end{tabular}


for poorly capitalized banks. For those banks an increase in equity capital results in a substantial decrease in systemic risk. For well capitalized banks, additional equity will not reduce systemic risk significantly.

\section{Conclusion}

This paper proposes a new method for monitoring the risk in a bank regulator's portfolio. Using stock-market information, I estimate the joint dynamics of bank's asset portfolios for a sample of international banks. Median correlations are positive and stable over time. Since 1997, however, correlations have substantially increased for North American banks and to some extent for European banks. Median volatilities are increasing around 1999 and 2000 for European and North American banks. The median capitalization stays constant. An increase in the capital base of the North American banks is offset by a decrease in the capitalization ratio of the Japanese banks in the sample.

Using the joint dynamics of the banks' investments, I estimate the probability of a simultaneous default of several banks, which is decreasing over time for the North American banks and increasing for Japanese banks. Interpreting the present value of expected shortfall as a put option on the bank's assets, the value and the volatility of expected shortfall can be derived. The contribution of banks in a particular region to overall shortfall risk can be estimated using standard tools of modern risk management. The value of the regulator's liability increased sharply at the time of the Asian crisis in 1997/98, while the volatility stays at a high level during the sample period. The Japanese banks contribute most to the volatility in the sample period.

The method proposed here is easy to implement and allows bank regulators to keep track of the risk within their banking system on an ongoing basis. It allows comparing the risk over time as well as between countries. The analysis relies on techniques that regulators require banks to implement and that are standard in risk management. The method here can easily be extended to wider datasets and high frequency data. The 
method can also be refined using more sophisticated value-at-risk models for options to compute the volatility of the expected shortfall. 


\section{References}

Acharya, Viral V., 2001, A Theory of Systemic Risk and Design of Prudential Bank Regulation, Working Paper, London Business School.

Aharony, Josef, and Itzhak Swary, 1983, Contagion Effects of Bank Failures: Evidence from Capital Markets, Journal of Business 56, 305-317.

Akhigbe, Aigbe, and Jeff Madura, 2001, Why do Contagion effects vary among bank faulures?, Journal of Banking and Finance 25, 657-680.

Allen, Franklin, and Douglas Gale, 2000, Financial Contagion, Journal of Political Economy 108, 1-34.

Allen, Linda, and Anthony Saunders, 1993, Forbearance and valuation of deposit insurance as a callable put, Journal of Banking and Finance 17, 629-643.

Black, Fischer, and Myron Scholes, 1973, The pricing of options and corporate liabilities, Journal of Political Economy 8, 1637-1659.

Borio, Claudio, 2003, Towards a macroprudential Framework for financial supervision and regulation?, BIS Working Paper No. 128.

Calomiris, Charles W., and Joseph R. Mason, 1997, Contagion and Bank Failures During the Great Depression: The June 1932 Chicago Banking Panic, Anerican Economic Review 87, 863-883.

Calomiris, Charles W., and Joseph R. Mason, forthcoming, Fundamentals, Panics, and Bank Distress in the Great Depression, American Economic Review.

Cooperman, Elizabeth S., Winson B. Lee, and Glenn A. Wolfe, 1992, The 1985 Ohio Thrift Crisis, the FSLICs Solvency, and Rate Contagion for Retail CDs, Journal of Finance 47, 919-941.

De Bandt, Olivier, and Philipp Hartmann, 2000, Systemic Risk: A Survey, European Central Bank Working Paper No. 35.

De Nicolo, Gianni, and Myron L. Kwast, 2002, Systemic Risk and Financial Consolidation: Are They Related?, Journal of Banking and Finance 26, 861-880.

Docking, Diane S., Mark Hirschey, and Elaine Jones, 1997, Information and Contagion Effects of Bank Loan-loss Reserve Announcements, Journal of Financial Economics 43, 219-240.

Dow, James, 2000, What is Systemic Risk? Moral hazard, initial shocks and propagation, Monetary and Economic Studies 18, 1-24. 
Duan, Jin-Chuan, 1994, Maximum Likelyhood Estimation using the Price Data of the Derivative Contract, Mathematical Finance 4, 155-167.

Duan, Jin-Chuan, 2000, Correction: Maximum Likelyhood Estimation using the Price Data of the Derivative Contract, Mathematical Finance 10, 461-462.

Duan, Jin-Chuan, Arthur F. Moreau, and C. Sealey, 1992, Fixed-rate deposit insurance and risk-shifting behavior at commercial banks, Journal of Banking and Finance 16, $715-742$.

Duan, Jin-Chuan, and Jean G. Simonato, 2002, Maximum Likelihood Estimation of Deposit Insurance Value with Interest Rate Risk, Journal of Empirical Finance 9, 109-132.

Duan, Jin-Chuan, and Min-Teh Yu, 1999, Capital Standard, Forbearance and Deposit Insurance Pricing under GARCH, Journal of Banking and Finance 23, 1691-1706.

Elsinger, Helmut, Alfred Lehar, and Martin Summer, 2002, Risk assessment for banking systems, working paper, University of Vienna.

Ericsson, Jan, and Joel Reneby, 1999, A note on contingent claims pricing with non traded assets, mimeo, McGill University.

Ericsson, Jan, and Joel Reneby, 2001, The Valuation of Corporate Liabilities: Theory and Tests, mimeo, McGill University.

Flannery, Mark J., and Kasturi P. Rangan, 2002, Market Forces at Work in the Banking Industry: Evidence from the Capital Buildup of the 1990s, Working Paper, University of Florida.

Freixas, Xavier, Bruno M. Parigi, and Jean-Charles Rochet, 2000, Systemic Risk, Interbank Relations, and Liquidity Provision by the Central Bank, Journal of Money, Credit, and Banking 32, 611-638.

Furfine, C., 2003, Interbank Exposures: Quantifying the Risk of Contagion, Journal of Money, Credit, and Banking 35, 111-128.

Giammarino, Ron, Eduardo Schwartz, and Josef Zechner, 1989, Market Valuation of Bank Assets and Deposit Insurance in Canada, Canadian Journal of Economics 22, 109-127.

Gizycki, Marianne C., and Mark Levonian, 1993, A Decade of Australian Banking Risk: Evidence from Share Prices, Research Discussion Paper 9302, Reserve Bank of Austrailia. 
Greenspan, Alan, 1997, Statement by Alan Greenspan Chairman Board of Governors of the Federal Reserve System before the Subcommittee on Capital Markets, Securities and Government Sponsored Enterprises of the Committee on Banking and Financial Services U.S. House of Representatives.

Gropp, Reint, Jukka Vesala, and Giuseppe Vulpes, 2002, Equity and Bond Market Signals as Leading Indicators of Bank Fragility, European Central Bank, Working Paper No. 150.

Hoggarth, Glenn, Ricardo Reis, and Victoria Saporta, 2002, Costs of banking system instability: some empirical evidence, Journal of Banking and Finance 26, 825-855.

Hovakimian, Armen, and Edward J. Kane, 2000, Effectiveness of Capital Regulation at U.S. Commercial Banks, 1985 to 1994, Journal of Finance 55, 451-468.

Jorion, Philippe, 2000, Value-at-Risk. (McGraw-Hill) second edn.

J.P.Morgan/Reuters, 1996, RiskMetrics-Technical Document. (J.P.Morgan).

Karafiath, Imre, Ross Mynatt, and Kenneth L. Smith, 1991, The Brazilian Default Announcement and the Contagion Effect Hypothesis, Journal of Banking and Finance 15, 699-716.

Kaufman, George, 2000, Banking and Currency Crises and Systemic Risk: a Taxonomy and Review, Financial Markets, Institutions and Instruments 9.

Krainer, John, and Jose A. Lopez, 2001, Incorporating Equity Market Information into Supervisory Monitoring Models, Federal Reserve Bank of San Francisco Working Paper 01-14.

Kupiec, Paul H., 1995, Techniques for Verifying the Accuracy of Risk Measurement Models, Journal of Derivatives 3, 73-84.

Laeven, Luc, 2002, Banking Risks around the World - The Implicit Safety Net Subsidy Approach, working paper, World Bank.

Madura, Jeff, Ann M. White, and Wm. R. McDaniel, 1991, Reaction of British Bank Share Prices to Citicorp's announces $\$ 3$ Billion Increase in Loan-loss Reserves, Journal of Banking and Finance 15, 151-163.

Merton, Robert C., 1973, A Rational Theory of Option Pricing, Bell Journal of Economics and Management Science 4, 141-183.

Merton, Robert C., 1974, On the pricing of corporate debt: The risk structure of interest rates, Journal of Finance 29, 449-470.

Merton, Robert C., 1977, An analytic derivation of the cost of deposit insurance and loan guarantees: An application of modern option pricing theory, Journal of Banking and Finance 1, 3-11. 
Merton, Robert C., 1978, On the cost of Deposit Insurance When There Are Surveillance Costs, Journal of Business 51, 439-452.

Nickell, Pamela, and William Perraudin, 2001, How Much Bank Capital is needed to maintain financial Stability?, working paper.

Ronn, E.I., and A.K. Verma, 1986, Pricing Risk-Adjusted Deposit insurance: An OptionBased Model, Journal of Finance 41, 871-895.

Ronn, E., and A. Verma, 1989, Risk-based Capital Adequacy Standards for a Sample of 43 Banks, Journal of Banking and Finance pp. 21-29.

Saunders, Anthony, and Berry Wilson, 1996, Contagious Bank Runs: Evidence from the 1929-33 Period, Journal of Financial Intermediation 5, 409-423.

Schoenmaker, Dirk, 1998, Contagion Risk in Banking, Proceedings of the second joint central bank research conference, Tokyo.

Shimizu, Tokiko, and Takashi Ui, 1999, Contagious Expectations and Malfunctions of Markets: Some Lessons from Japanese Financial Institution Failures of 1997, IMES Discussion Paper No. 99-E-3.

Slovin, Myron B., Marie E. Sushka, and John A. Polonchek, 1999, An analysis of Contagion and Competitive Effects at Commercial Banks, Journal of Financial Economics 54, 197-225.

Summer, Martin, 2003, Banking Regulation and Systemic Risk, Open Economies Review.

Swary, Itzhak, 1986, Stock Market Reaction to Regulatory Action in the Continental Illinois Crisis, Journal of Business 59, 451-473.

Vassalou, Maria, and Yuhang Xing, 2004, Default Risk in Equity Returns, Journal of Finance 59, 831-868. 


\section{A Summary statistics of regression variables}

The following table contains summary statistics of regression explanatory variables and the regulatory capitalization ratio for the whole sample and the three different subsamples. Bank size (SIZE) is measured as log of the book value of total assets measured in million US-Dollars, return on assets (ROA) is measured as net income over book value of total assets in percent, and equity (EQBK) is the book value of equity over total assets in percent. Long term debt (LTDEBT) is defined as debt (including deposits) with a maturity over one year over total debt, and regulatory capitalization (CAPRAT) is defined as the ratio of regulatory capital (Tier $1+$ Tier 2) over risk weighted assets in percent.

\begin{tabular}{lrrrrrrr} 
& Min & $25 \%$ & median & $75 \%$ & Max & mean & Stddev \\
\hline SIZE & 4.6607 & 10.1853 & 10.8805 & 11.6786 & 13.6906 & 10.8934 & 1.3232 \\
US & 8.4075 & 10.2938 & 10.8053 & 11.5312 & 13.5395 & 10.8961 & 0.9385 \\
EU & 4.6607 & 10.1298 & 11.1450 & 11.9147 & 13.6906 & 10.7453 & 1.8415 \\
JP & 8.7306 & 10.1500 & 10.8449 & 11.7443 & 13.6901 & 11.0084 & 1.1096 \\
\hline ROA & -9.9980 & 0.1130 & 0.2885 & 0.8640 & 3.9870 & 0.4401 & 0.8424 \\
US & -2.6020 & 0.6130 & 1.0000 & 1.3360 & 2.5160 & 0.9365 & 0.5800 \\
EU & -2.9010 & 0.2230 & 0.4090 & 0.8200 & 3.9870 & 0.5890 & 0.6915 \\
JP & -9.9980 & 0.0270 & 0.0985 & 0.1770 & 2.6240 & -0.1264 & 0.8176 \\
\hline EQBK & -0.0063 & 0.0374 & 0.0470 & 0.0653 & 0.4198 & 0.0550 & 0.0366 \\
US & 0.0381 & 0.0523 & 0.0673 & 0.0791 & 0.1099 & 0.0669 & 0.0162 \\
EU & -0.0063 & 0.0337 & 0.0433 & 0.0593 & 0.4198 & 0.0587 & 0.0610 \\
JP & 0.0092 & 0.0340 & 0.0397 & 0.0462 & 0.0856 & 0.0410 & 0.0105 \\
\hline LTDEBT & 0.0000 & 0.0173 & 0.0347 & 0.0984 & 0.8358 & 0.0926 & 0.1430 \\
US & 0.0016 & 0.0229 & 0.0454 & 0.0889 & 0.3187 & 0.0652 & 0.0574 \\
EU & 0.0000 & 0.0374 & 0.1239 & 0.2821 & 0.8358 & 0.1929 & 0.1983 \\
JP & 0.0000 & 0.0079 & 0.0182 & 0.0303 & 0.6912 & 0.0417 & 0.1054 \\
\hline CAPRAT & 0.5000 & 9.3450 & 10.7000 & 12.0950 & 28.6600 & 10.8559 & 2.3631 \\
US & 1.0310 & 10.0000 & 11.4600 & 12.5000 & 28.6600 & 11.5165 & 2.6627 \\
EU & 0.5000 & 9.9000 & 11.0000 & 12.5350 & 18.2100 & 11.1467 & 2.2420 \\
JP & 2.9900 & 8.8700 & 9.4350 & 10.3900 & 13.9400 & 9.7425 & 1.3887 \\
\hline & & & & & & &
\end{tabular}

\section{B Monte Carlo simulation}

I assume that the value of each bank's total assets, denoted by $V_{i}$ under the objective probability measure is governed by a Geometric Brownian motion

$$
d V_{i}=\mu_{i} V_{i} d t+V_{i} d X_{i}
$$


where $X_{i}$ is the $i$-th element of $X$, an $n$-dimensional Brownian motion with variancecovariance matrix $\Sigma$. The important innovation in this research is that I explicitly allow the asset values of different banks to be correlated. Thus, $V_{i}(t)$ can be written as

$$
V_{i}(t)=V_{i}(0) * \exp \left(\mu_{i} t+X_{i}(t)-\frac{1}{2} \sigma_{i i}^{2} t\right)
$$

where $X(t)$ is multivariate normally distributed with $E[X(t)]=0_{n, 1}$ and $\operatorname{Var}[X(t)]=$ $t \Sigma$. $0_{n, 1}$ denotes an $n \times 1$ vector of zeros and $\Sigma$ is the $\mathrm{n}$-dimensional variance-covariance matrix. $\sigma_{i i}^{2}$ is the $\mathrm{i}$-th diagonal element of $\Sigma$. To generate scenarios I simulate $V_{i}(T)$ simultaneously for all banks, i.e., I have to use the same realization of $X(T)$ for all banks. Let us denote the simulation $s$ by $V^{s}(T)$.

Using the Cholesky decomposition 30 one can represent $\Sigma$ as $U^{T} U$ where $U$ is an n-dimensional upper triangular matrix. Let $Y \sim N\left(0_{n, 1}, I_{n, n}\right)$ and define $W=U^{T} Y$. Then $W$ has the same distribution as $X$, i.e., $W \sim N\left(0_{n, 1}, \Sigma\right)$. To generate a scenario $s$ I randomly draw an $n \times 1$ vector $\hat{Y}^{s}$ of independent standard normal random variables. I substitute the estimated variance-covariance matrix $\hat{\Sigma}$ for the unknown $\Sigma$ and decompose $\hat{\Sigma}$ into $\hat{U}^{T} \hat{U}$ using the Cholesky factorization. Pre-multiplying $\hat{Y}^{s}$ with $\hat{U}^{T}$ and rescaling for time yields

$$
\hat{W}^{s}=\sqrt{T} \hat{U}^{T} \hat{Y}^{s}
$$

Now, $V_{i}^{s}(T)$ is calculated as

$$
V_{i}^{s}(T)=V_{i}(0) * \exp \left(\hat{\mu}_{i} T+\hat{W}_{i}^{s}-\frac{1}{2} \hat{\sigma}_{i i}^{2} T\right)
$$

where $\hat{\sigma}_{i i}^{2}$ is the $\mathrm{i}-$ th diagonal element of $\hat{\Sigma}$. This way it is possible to simulate the joint process of all banks' asset values using the estimated covariance structure.

\section{Numerical accuracy simulations}

The following table shows the mean and standard errors (in brackets) of the systemic risk indices for different numbers of runs in the Monte Carlo simulation. SIV $(\mathrm{x})$ is the probability that banks with total assets of $x \%$ of all banks' total assets will go bankrupt over the next six month. $\mathrm{SIN}(\mathrm{x})$ is the probability that $\mathrm{x} \%$ of all banks fail over the same horizon.

\footnotetext{
${ }^{30}$ For the Cholesky Decomposition approach, see ? Appendix E
} 


\begin{tabular}{lrrr} 
& \multicolumn{3}{c}{ Number of runs in MC simulation } \\
\cline { 2 - 4 } & 1 million & 2 million & 4 million \\
\hline SIV(5\%) & $13.5086 \%$ & $13.5087 \%$ & $13.5092 \%$ \\
& $(0.0357 \%)$ & $(0.0231 \%)$ & $(0.0171 \%)$ \\
SIV $(10 \%)$ & $5.1290 \%$ & $5.1283 \%$ & $5.1278 \%$ \\
& $(0.0218 \%)$ & $(0.0150 \%)$ & $(0.0112 \%)$ \\
SIV $(15 \%)$ & $0.7664 \%$ & $0.7664 \%$ & $0.7664 \%$ \\
& $(0.0084 \%)$ & $(0.0060 \%)$ & $(0.0043 \%)$ \\
\hline SIN(5\%) & $14.8922 \%$ & $14.8931 \%$ & $14.8911 \%$ \\
& $(0.0364 \%)$ & $(0.0232 \%)$ & $(0.0181 \%)$ \\
SIN $(10 \%)$ & $3.6501 \%$ & $3.6490 \%$ & $3.6488 \%$ \\
& $(0.0171 \%)$ & $(0.0122 \%)$ & $(0.0095 \%)$ \\
SIN $(15 \%)$ & $0.1258 \%$ & $0.1256 \%$ & $0.1258 \%$ \\
& $(0.0038 \%)$ & $(0.0026 \%)$ & $(0.0018 \%)$ \\
\hline
\end{tabular}

Not surprisingly, one can see a decline in standard errors as the number of runs increases and lower precision for smaller quantiles. Nevertheless standard errors are quite small. All risk indices are computed for the North American sub-sample using an equally weighted variance-covariance matrix over a period from 1988 until 2000. The means and standard deviations are estimated by repeating the simulations 400 times. The random number generator of Microsoft Visual C++ was used to conduct the simulation. 